
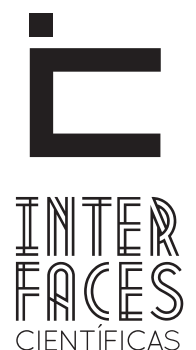

EDUCAÇÃO

ISSN IMPRESSO 2316-333X

ISSN ELETRÔNICO 2316-3828

DOI 10.17564/2316-3828.2015v4n1p67-76

\title{
REVENDO A HISTÓRIA DO COLÉGIO DE APLICAÇÃO DA UNIVERSIDADE ESTADUAL DE LONDRINA: PASSADO, PRESENTE E FUTURO
}

Adriana Regina de Jesus Santos ${ }^{1}$

Fábio Luiz da Silva ${ }^{3}$
Marta Regina Furlan de Oliveira ${ }^{2}$

\section{RESUMO}

Partindo da premissa de que em cada época e lugar, tem se constituído um tipo de sociedade, de educação e indivíduo, objetivamos nesse artigo, tecer algumas reflexões que se fazem necessárias para compreender o processo histórico da constituição do Colégio de Aplicação da Universidade Estadual de Londrina a fim de entender a sua natureza histórica, tendo como parâmetro as influências do modelo econômico e pedagógico brasileiro da década de 1930 até os dias atuais. Na busca de recuperar a trajetória histórica da criação dos Colégios de Aplicação no Brasil e especificamente do Colégio de Aplicação da Universidade Estadual de Londrina, a pesquisa bibliográfica e a análise documental formaram o conjunto de procedimentos investigativos. Tendo como parâmetro o Plano Decenal de Educação Para Todos (BRASIL, 2003) pode-se constatar que a criação dos Colégios de Aplicação, enquanto campo de experimentação para se pensar em novas metodologias didáticas, possibilitando a articulação entre ensino superior e educação básica teve como influência as teorias de Rousseau e Dewey.

\section{PALAVRAS-CHAVE}

Educação. Colégio de Aplicação. Formação de Professor. Universidade. 


\section{ABSCTRACT}

Starting from the premise that in every time and place, has been a kind of society, education and individual aim in this article, make some reflections that are necessary to understand the historical process Application College of constitution of the State University of London in order to understand its historical nature having as parameter the influences of Brazilian economic and pedagogical model of the 1930s to the present day. In the quest to recover the historical trajectory of the creation of Application Colleges in Brazil and specifically the application of the College of the State University of Londrina, bibliographical research and document analysis formed the set of in-

\section{RESUMEN}

Partiendo de lapremisa de que en todo tiempo y lugar, ha sido una especie de sociedad, laeducación y el objetivo individual en este artículo, haceralgunas reflexiones que sonnecesarios para comprenderelproceso histórico ColegioAplicación de constitución de laUniversidaddel Estado de Londres conelfin de entender sunaturaleza histórica teniendo como parámetro de las influencias del modelo económico y pedagógico brasileño de la década de 1930 hasta laactualidad. Enlabúsqueda de recuperar latrayectoria histórica de lacreación de Colegios de aplicacionesen Brasil y, específicamente, laaplicación de laFacultad de laUniversidad Estadual de Londrina, investigación y análisis de documentos bibliográficos formóel conjunto vestigative procedures. Having as parameter the Ten Year Plan for Education for All (BRAZIL, 2003) can be seen that the creation of Application Colleges as experimental field to think of new teaching methodologies, enabling the link between higher education and basic education had as influences the theories of Rousseau and Dewey.

\section{KEYWORDS}

\author{
Education. College Application.Teacher Training. \\ University.
}

de procedimientos de investigación.Teniendo como parámetroelPlan Decenal de Educación para Todos (BRASIL, 2003) se puede ver que lacreación de Colegios de aplicaciones como campo experimental para pensar ennuevasmetodologías de enseñanza, lo que permite el enlace entre laeducación superior y laeducación básica tenido como influencias lasteorías de Rousseau y Dewey.

\section{PALABRAS CLAVE}

Educación. Aplicación de Launiversidad. La formación Del Profesorado. Universidad. 


\section{INTRODUÇ̃̃O}

Partindo da premissa de que em cada época e lugar, tem se constituído um tipo de sociedade, de educação e indivíduo, objetivamos neste artigo, tecer algumas reflexões que se fazem necessárias no processo de compreensão da existência do Colégio Estadual Professor José Aloísio Aragão - Colégio de Aplicação da Universidade Estadual de Londrina.

Na busca pela compreensão da história dos mais de 50 anos dessa Instituição, faremos a seguir um breve relato histórico-político e pedagógico sobre a origem dos Colégios de Aplicação no Brasil e no Estado do Paraná. Com um olhar voltado para o contexto de seu surgimento até a atualidade, procuramos entender os desafios postos pela relação entre Universidade e Educação Básica.

Conforme dados históricos, em 1931 foi aprovada uma legislação (Decreto no 19.851, de 11 de Abril de 1931) para o Ensino Superior no Brasil. Previa-se, a partir da nova legislação, que as Faculdades de Filosofia, Ciências e Letras fossem, além de lugares de pesquisa, instrumentos para a formação de professores para a Educação Básica. Nesse sentido, o Decreto no 19.851, de 11 de Abril de 1931 afirma por meio do seu artigo $1^{\circ}$, que:

O ensino universitário tem como finalidade: elevar o nível da cultura geral, estimular a investigação cientifica em quaisquer domínios dos conhecimentos humanos; habilitar ao exercício de atividades que requerem preparo técnico e científico superior; concorrer, enfim, pela educação do indivíduo e da coletividade, pela harmonia de objetivos entre professores e estudantes e pelo aproveitamento de todas as atividades universitárias, para a grandeza da Nação e para o aperfeiçoamento da Humanidade. (BRASIL, 1931, on-line).

No Plano Decenal de Educação Para Todos (BRASIL, 2003), na série "Repensando as Escolas de Aplicação", encontramos elementos significativos a respeito desse processo histórico:

\begin{abstract}
A origem das Escolas de Aplicação remete-nos ao Decreto-Lei no 9.053, de 12 de março de 1946, que criou os Ginásios de Aplicação, nas Faculdades de Filosofia do País, para a prática docente dos alunos matriculados no Curso de Didática. Pelo Decreto, os Ginásios de Aplicação teriam como dirigentes um professor de Didática, ficando a orientação pedagógica a cargo dos assistentes de Didática Especializada, sob a orientação geral do diretor da Faculdade de Filosofia. O corpo docente seria constituído, especialmente, pelos alunos do Curso de Didática que seriam encarregados das diferentes disciplinas do Curso Ginasial. (BRASIL, 2003, p. 28).
\end{abstract}

A partir do Decreto 3.0178 de 20 de junho de 1960, Moisés Lupion, então governador do Paraná, criou o Ginásio Estadual de Aplicação. Tal medida colocava em prática o disposto no Decreto Federal 9.053 de 1946, que obrigava as faculdades de Filosofia, Ciências e Letras possuírem escolas onde os futuros professores pudessem realizar seus estágios. Em geral, esses estabelecimentos deveriam seguir a Lei Orgânica do Ensino Secundário, mas com algumas diferenças como, por exemplo, a limitação de alunos por turma - que nos Ginásios de Aplicação seriam, no máximo, para 30 alunos.

A criação de um Colégio de Aplicação, no entanto, não pode ser explicada pelo simples cumprimento de uma determinação legal. Para entendermos melhor os fatores que levaram ao estabelecimento do Ginásio de Aplicação (hoje, órgão suplementar da Universidade Estadual de Londrina), é necessário retornar aos conturbados anos 20 , analisando o próprio contexto e o processo de surgimento do Colégio de Aplicação, a fim de propormos novos horizontes pedagógicos na parceria entre Universidade e Educação Básica.

\section{REVENDO O PASSADO: 0 CONTEXTO}

A prosperidade e o otimismo da economia norte-americana dos anos iniciais da década de 1920 foram colocados à prova depois da crise de 1929. Esta rapi- 
damente alastrou-se pelo mundo e foi um dos fatores que levaram a modificações na estrutura social e econômica brasileira. Enquanto a chamada Revolução de 30 pode ser entendida como representação política desses acontecimentos, o crescimento de uma camada média e urbana pode ser vista como exemplo das modificações sociais em andamento. Na esfera econômica, podemos indicar que o modelo produtivo do país, que até então era quase totalmente agrário, passava a ser cada vez mais industrial.

Até os anos 30, em uma sociedade plenamente baseada na agricultura, a necessidade de instrução não era sentida pela maioria da população, tampouco pelos governantes - em geral oriundos das oligarquias agrárias. Mas a situação alterou-se depois da década de 1930, quando as modificações na sociedade brasileira geraram novas aspirações sociais que somente poderiam ser atendidas com transformações no sistema educacional (FRANGELLA, 2009).

Com o novo modelo econômico e na nova ordem política estabelecida no país a partir da década de 1930, o Estado passou a adotar a postura de oferecer à população a instrução necessária para um Brasil cada vez mais urbano e industrializado. Um bom exemplo disso foi a criação do Ministério da Educação e Saúde Pública, em 1930. Como consequência desse processo, o sistema de ensino proporcionou - mesmo que de forma limitada - oportunidade de mobilidade social via educação.

Na realidade, como vemos no Plano Decenal de Educação Para Todos (BRASIL, 2003, p. 34) "a natureza dos vínculos entre as instituições de Ensino Superior e seus Colégios de Aplicação foi muito variável, bem como a estrutura proposta”. 0 traço comum dessas escolas foi a abertura aos licenciados, para observação, coparticipação e regência de algumas aulas. Ao praticarem, em suas classes, o saber adquirido na Faculdade, os alunos-mestres estariam aplicando as teorias pedagógicas à realidade escolar.
Discutia-se, à época, a função possível dessas instituições, como ponta-de-lança da pesquisa educacional, nos moldes dos TeachersCollege americanos ou do "Instituto J. J. Rousseau”, de Genebra. Novas utopias que refletiam o anseio nacional pela renovação pedagógica, a partir da experimentação de novos meios e pela revisão dos objetivos, quando se chegava ao meio do século e ao final da $2^{a}$ Guerra Mundial. Nesse período, eram divulgadas em nosso País, diretamente ou traduzidas e comentadas, as obras pedagógicas americanas ou europeias sobre as teses da Escola Nova, que renasciam no pós-guerra. No Brasil, que encerrava o período do Estado Novo, difundiam-se o ideário liberal-democrata, as preocupações sociais e a integração dos sistemas de ensino até então separados: o profissional e o "secundário", que ainda suportava a pecha de ensino "de passagem” para a Universidade. (BRASIL, 2003, p. 45).

De acordo com o mesmo documento (BRASIL, 2003, p. 16), a ideia de experimentação com classes ou escolas difundiu-se e foi objeto de legislação especial, antes de passar a fazer parte da Lei 4.024/61. As Escolas de Aplicação pareciam ser campos convenientes para a experiência de novos modelos de organização e de metodologia didática, o que contribuiu para que se diferenciassem cada vez mais das outras escolas mantidas pelas Secretarias de Estado e de Municípios.

Com a publicação do Parecer 292/62, do Conselho Federal de Educação, eliminou-se a obrigatoriedade das Escolas de Aplicação, alterando assim, o elenco das disciplinas pedagógicas, dando-se, então, a seguinte orientação à formação prática do licenciado: é também obrigatória, sob a forma de estágio supervisionado, a prática de ensino das matérias que sejam objeto de habilitação profissional (BRASIL, 2003).

Segundo dados do Plano Decenal de Educação Para Todos (BRASIL, 2003), o relator do Parecer do CFE 292/62, conselheiro Valnir Chagas, procurou redefinir as Escolas de Aplicação, entendendo-as como "centros de experimentação e demonstração", mas julgando que a prática de ensino deveria ser realizada nas próprias escolas da comunidade e, de modo semelhante, aos internatos dos cursos de Medicina. 
Inclinou-se, assim, para um sistema no qual a supervisão dos estágios fosse realmente exercida e que, ao mesmo tempo, envolvesse as escolas da comunidade num processo de renovação. A denominação "Ginásio de Aplicação" foi, ao longo do tempo, sendo substituída por "Escola de Aplicação", uma vez que, ao lado do Curso Ginasial, muitos deles passaram a oferecer o Curso Colegial e/ou Curso Normal e, por último, as Séries Iniciais do $1^{\circ} \mathrm{Grau}$. Essa legislação, no que diz respeito à prática do ensino, não foi até a presente data alterada, não obstante as profundas modificações sofridas pelo sistema educacional brasileiro e pelo seu contexto social, econômico e político.

Diante disto, os Colégios de Aplicação foram criados com o objetivo de proporcionar um lugar onde os futuros professores pudessem entrar em contato com o cotidiano escolar, preparando-os para a sua atuação profissional.

Faz-se necessário ressaltar, que por meio dos dados históricos acerca da criação do Colégio de Aplicação foi possivel perceber, também, que estes tiveram uma forte influência das teorias de Rousseau e Dewey no que se refere a nova concepção de educação no Brasil, que permeava o contexto da sociedade no que tange ao inicio do século XX. Sendo assim, o questionamento em torno do papel da educação neste momento foi alimentado, primordialmente, pela filosofia pragmática, que terá em John Dewey seu grande sistematizador. Essa teoria da vida e da experiência humana vê o homem basicamente como um organismo, situado num ambiente que se modifica e se refaz continuamente.

Portanto, o homem sofre estas modificações e nelas intervém em seu próprio benefício. Daí a importância de conhecer as funções das coisas em seu meio ambiente. 0 que importa não é a natureza abstrata de um dado objeto, mas suas operações e relações no mundo de nossa experiência. Dessa forma, os Colégios de Aplicação tinham como principio proporcionar aos alunos, por meio da práxis pedagógica, desenvolver habilidades de observar, pensar, julgar, criar, decidir e agir.
Pensado assim, os Colégios de Aplicação seriam para as licenciaturas o que um escritório de aplicação é para o curso de Direito ou um hospital universitário para o curso de Medicina. Os Colégios de Aplicação deveriam ser também, um lugar para a pesquisa pedagógica, com o objetivo de trazer contribuições científicas ao processo de ensino e aprendizagem.

Apesar de todo o mérito da proposta inicial em relação aos Colégios de Aplicação, a partir dos anos 50 do século $X X$, estes foram perdendo sua identidade política e pedagógica. Em 1961, o Conselho Federal de Educação (CFE) foi criado com a implantação da Lei de Diretrizes e Bases da Educação Nacional (4024/61).

Como já afirmamos, no ano seguinte, o parecer 292/62 do CFE estabeleceu que a prática do ensino deveria ocorrer preferencialmente em escolas da comunidade. Na prática, isso significava o fim da obrigatoriedade da existência dos Colégios de Aplicação vinculados às instituições de ensino superior (KINPARA, 1997, p.37). A essa altura, porém, o Colégio de Aplicação de Londrina já havia sido criado.

Essa diferenciação contribuiu para um distanciamento entre os Colégios de Aplicação e as Licenciaturas e, ao mesmo tempo, permitiu a construção de críticas à sua própria existência. Hoje, as Licenciaturas realizam os estágios obrigatórios em qualquer estabelecimento de ensino e poucas pesquisas são realmente efetivadas nos Colégios de Aplicação.

No caso do Colégio de Aplicação da Universidade Estadual de Londrina, isto pode ser percebido pela perda de sua importância político-institucional. A demonstração mais evidente disso pode ser facilmente constatada pela paulatina diminuição do espaço físico a ele destinado: o edifício e o terreno foram sendo ocupados por outros setores da universidade e, até mesmo, pelo DCE que utilizou uma casa onde antes ocorriam aulas de Iniciação às Técnicas de Trabalho. Além dos aspectos físicos, a crise de identidade do Colégio pode ser também confirmada pela estrutura administrativa/ 
pedagógica com “dupla cidadania”, isto é, dividida com a Secretaria de Educação do Estado do Paraná.

\section{REVENDO 0 PASSADO: 0 COLÉGIO}

O Colégio (no começo chamado Ginásio) de Aplicação da Universidade Estadual de Londrina nasceu antes mesmo da criação da Universidade, sendo que esta foi criada apenas em 1970. Já havia outros ginásios no Brasil, por exemplo, o Colégio de Demonstração ligado à Faculdade Nacional de Filosofia, fundado em 1948. Hoje, há 21 escolas com as características “de aplicação”, isto é, vinculadas a instituições de Ensino Superior. 0 objetivo de seu surgimento foi para atender o disposto pelo Decreto Lei Federal nº 9053 de 12/3/1946, que exigia do Colégio de Aplicação Pedagógica anexos às Faculdades de Filosofia, Ciências e Letras que formavam professores, visando contribuir nesta formação por meio de oferta de campos de estágios curriculares e de experimentação pedagógica aos educandos de graduação.

Faz-se necessário ressaltar, que na noite de 4 de maio de 1960, reuniu-se a Congregação da Faculdade Estadual de Filosofia, Ciências e Letras de Londrina. Era uma convocação extraordinária e destinava-se à discussão da criação ou não de dois novos cursos: Didática e Pedagogia. 0 primeiro deveria atender à complementação de estudos dos bacharéis de diversos cursos. 0 curso de Pedagogia, por sua vez, atenderia a grande demanda existente em Londrina e região, em especial à necessidade de professoras normalistas. Aprovada a proposta após breve discussão, foi criado, também, um Ginásio de Aplicação para atender aos alunos do curso de Didática.

Inicialmente, o Ginásio de Aplicação atendia tão somente alunas, já que o curso era totalmente feminino, e funcionava em dois períodos. Pela manhã, aulas normais dos conteúdos propostos pelo programa; à tarde havia uma espécie de complementação curricular por meio de estudos dirigidos orientados por estagiários, com duração de três horas.
Atualmente o Colégio de Aplicação, também conhecido como "Colégio Estadual Professor José Aloísio Aragão" constitui-se como um Órgão Suplementar da Universidade Estadual de Londrina, vinculado ao Centro de Educação, Comunicação e Artes e pedagogicamente ao Departamento de Educação. Através desse é ofertada a Educação Básica por meio dos seguintes níveis de ensino: Educação Infantil, Anos Iniciais e Finais do Ensino Fundamental; Ensino Médio e Ensino Profissionalizante (Curso Técnico de Enfermagem e Curso Técnico de Cuidados com a pessoa Idosa). O Colégio tem servido como campo de estágio para os cursos de licenciatura e algumas pesquisas discentes e docentes da Universidade Estadual de Londrina.

Os recursos materiais e humanos são oriundos da Secretaria de Educação a Distância/Núcleo Regional de Educação-PR (SEED/NRE) e Universidade Estadual de Londrina. Na busca de atualização, ocorrem trocas de experiências entre estagiários, docentes de Instituições de Ensino Superior e docentes da Educação Básica, contribuindo assim, com o processo de ensino e aprendizagem. Além disso, a comunidade sempre está presente, apoiando a equipe administrativa e pedagógica nas decisões, em busca de uma educação de qualidade.

O Colégio possui um corpo de professores comprometido com o trabalho docente e, em termos de desempenho acadêmico, os alunos têm alcançado bons resultados no Exame nacional do ensino Médio (ENEM) e Prova Brasil. Em termos de composição social, a maioria dos alunos do colégio pertence às classes B1 e B2 $(70,1 \%)$ moram em diversas regiões da cidade, conforme dados extraídos da pesquisa realizada, utilizando como modelo "Critério de Classificação Econômica Brasil, da Associação Brasileira de Empresas de Pesquisa”. Ao contrário do que ocorria até certa época, hoje o Colégio de Aplicação não realiza mais o chamado "Vestibulinho" que, para os críticos de qualquer experiência de sucesso, elitizava o Colégio.

No ano de 2010, o Colégio de Aplicação recebeu a comenda Ouro Verde em decorrência do excelente 
trabalho realizado durante os cinquenta anos de sua exigência na cidade de Londrina. No entanto, mesmo constatando por meio da história da cidade o significativo trabalho dessa instituição, percebe-se a necessidade de investimento político voltado à estrutura administrativa e pedagógica do mesmo, podendo desta maneira, possibilitar uma autonomia pedagógica no que tange ao processo de ensino e aprendizagem.

\section{CONSTRUINDO O FUTURO: ARTICULAÇÃO EN- TRE UNIVERSIDADES E COLÉGIOS DE APLICAÇÃO}

O futuro e a ressignificação do Colégio de Aplicação estão intimamente ligados ao entendimento que se tem sobre a educação. 0 Colégio deverá tornar-se uma instituição onde se pratique educação de qualidade e de onde tal prática possa ser estendida às demais escolas da comunidade. Então, trata-se de garantir mais do que uma educação para todos, mas uma boa educação para todos (BRASIL, 1993).

Para que isso ocorra, é preciso que se estruture o Colégio com maior autonomia didática, administrativa e orçamentária. Libertando, assim, a instituição das limitações impostas pelo sistema estadual de educação. Feito isso, há a necessidade de melhoria dos caminhos da comunicação entre a Universidade, - Colégio e a comunidade, ou seja, uma maior autonomia somente tem sentido se houver maior contribuição do Colégio à comunidade escolar.

Destarte no ano de 2010 os Colégios de Aplicação da Universidade Estadual de Londrina, Universidade Estadual de Ponta Grossa e Universidade Estadual de Maringá se reuniram para solicitar que as Instituições de Ensino Superior assumissem definitivamente os Colégios de Aplicação, tendo como meta geral, pensar na definição de uma política de efetiva inserção das Escolas de Aplicação na estrutura universitária, que lhes possibilite grau maior de autonomia didática, administrativa e orçamentária, ao mesmo tempo em que favoreça relação de ensino, pesquisa e extensão, arti- culando assim, Educação Superior e Básica. Atualmente os Colégios de Aplicação apresentam dubiedade em relação à estrutura administrativa e pedagógica, isto é, existe um Termo de Cooperação Técnica entre Universidade e Secretaria do Estado de Educação do Paraná, o que implica na não autonomia dos Colégios.

Faz-se necessário ressaltar que esta luta está sendo constituída por meio de um grupo de trabalho tendo como participantes: membros do Fórum das Licenciaturas da Universidade Estadual de Londrina (FOPE), Programa de Consolidação das Licenciaturas (PRODOCENCIA), Reitores, diretores, professores e representantes dos funcionários das Instituições de Ensino Superior, Sindicatos, Conselho Estadual de Educação, Secretaria do Estado de Educação do Paraná e Secretaria de Estado da Ciência, Tecnologia e Ensino Superior (SETI).

Diante disso, é preciso referir-se à prática de ensino como uma ação pedagógica, conveniente e competentemente articulada, com as Escolas de Aplicação, com as Universidades, com os cursos de licenciatura e as escolas da comunidade, de modo a viabilizar a práxis pedagógica, priorizando a qualidade do ensino e a educação integral. Assim, torna-se exigência repensar, analisar, avaliar e questionar os modelos e paradigmas educacionais vigentes. Este novo paradigma filosófico, científico e educacional que se delineia no cenário mundial tem profundas implicações na vida social, exigindo uma política educacional com vistas a ressignificar a formação inicial e continuada.

Para isto é preciso que as Escolas de Aplicação busquem, efetivamente, por meio de sua práxis pedagógica, ações interdisciplinares, multidisciplinares, transdisciplinares, por meio de movimentos articulados intramuros, entre escolas e Universidade. Esta articulação permitiria às Escolas de Aplicação o inter-relacionamento, mais direto, com o conhecimento cientifico que a Universidade produz. Tudo isto favoreceria o acompanhamento do avanço do saber, nas diferentes áreas, enriquecendo, desta forma, as ações 
compartilhadas entre o Ensino Superior e Educação Básica. É na direção desse processo de transformação que as Escolas de Aplicação têm de redimensionar e redirecionar seu papel e suas ações (BRASIL, 2003).

É importante que as Escolas de Aplicação se orientem por princípios comuns, com vistas à sua maior qualificação, enquanto escola pública participante e compromissada com a qualificação de uma rede pública escolar mais democrática. Foi neste contexto que em fevereiro de 2012 realizou-se um evento para debater temas relacionados ao Ensino Superior e Educação Básica, com o titulo de I Congresso Nacional dos Colégios de Aplicação; e simultaneamente ocorreu a I Mostra de Práticas de Ensino de Estágios, do Programa Institucional de Bolsa de Iniciação à Docência (PIBID) e do PRODOCÊNCIA.

Este congresso teve como objetivo refletir sobre a origem, o conceito, a função social e a identidade dos Colégios de Aplicação em âmbito nacional e estadual. Buscou-se compreender melhor as políticas educacionais que norteiam a gestão dessas instituições, bem como a legitimação de políticas que garantam a articulação entre Ensino Superior e Educação Básica. Sobretudo, este evento pretendeu democratizar e socializar as práticas pedagógicas realizadas no cotidiano dos colégios de aplicação do país, oportunizando espaço de reflexão sobre a qualidade da educação pública.

Dito isto, com os debates promovidos no presente Congresso, por meio das palestras, oficinas, mesas redondas e grupos de trabalho, foi possível promover algumas ações, dentre elas a construção coletiva de um Manifesto em prol dos Colégios de Aplicação das Universidades Estaduais de Londrina, Maringá e Ponta Grossa. Neste manifesto foi apresentado algumas reivindicações em prol da autonomia administrativa e pedagógica dos Colégios de Aplicação, dentre elas podemos destacar:

a) Vinculação e manutenção dos Colégios de Aplicação pelas Universidades; b) Definição de uma política de efetiva inserção das Escolas de Aplicação na estrutura universitária, que possibilite grau maior de autonomia didática, administrativa e orçamentária, ao mesmo tempo em que fomente a relação entreensino, pesquisa e extensão, articulando assim, Educação Superior e Básica; c) Criação de mecanismo de interação sistemática entre as Escolas de Aplicação e as unidades universitárias responsáveis pela formação de recursos humanos para a Educação, com vistas a maior interação entre Escola de Aplicação e demais unidades universitárias e Educação Básica; d) Promover maior articulação entre as modalidades de ensino: Educação Infantil, Fundamental, Médio, Profissionalizante e Superior, através do debate de propostas de ensino, pesquisa e extensão, voltadas às reais necessidades dos CAPs e da potencialização da formação docente, geridas pelas universidades públicas envolvidas; e) Analisar o contexto dos Colégios de Aplicação em âmbito nacional, bem como, as suas contribuições no processo de ensino e aprendizagem, podendo assim, compreender as Políticas Públicas e Práticas Pedagógicas que norteiam os rumos da Educação Básica e do Ensino Superior (MANIFESTO, 2012).

Vale dizer que a construção das reivindicações que compuseram o referido Manifesto teve apoio e participação dos diretores das Universidades Estaduais de Maringá, Ponta Grossa, Universidade de São Paulo (USP) e das Universidades Federais do Rio Grande do Sul, Viçosa, Rio de Janeiro e representantes de outros dez Estados Brasileiros. Finalizou-se o manifesto, solicitando apoio e encaminhamentos em relação às reivindicações expressas, tendo em vista a aproximação entre universidade e Educação Básica, concretização do tripé ensino, pesquisa e extensão, e a luta para assegurar as condições necessárias para a oferta de educação publica de qualidade em nossas escolas. Também foram reivindicações desse grupo, pontuadas no manifesto;

f) Possibilitar espaço diferenciado de formação continuada para trabalhadores da educação, estudantes e pais, oriundos das redes públicas federais, estaduais e municipais, para discutir a melhoria da qualidade do ensino nos diferentes ambientes educacionais envolvidos; g) Proporcionar a disseminação das pesquisas sobre educação básica, educação superior, estágios, projetos, em especial dos resultados dos trabalhos que vêm sendo desenvolvidos pelo PIBID e pelo Prodocência por meio 
das universidades, em parcerias com a Educação Básica; h) Iniciar discussão sobre a constituição do quadro funcional dos Colégios de Aplicação; i) Socializar conhecimentos e firmar parcerias entre os Colégios de Aplicação do Brasil, visando à construção e à ampliação de uma rede de comunicação destinada às trocas de informações e experiências administrativas e pedagógicas entre estas instituições; j) Discutir a concepção de Colégios de Aplicação no Brasil, ressaltando o papel público educacional que estes representam no cenário da política educacional, tendo como parâmetro a autonomia pedagógica e administrativa; k) Melhorar a qualidade dos estágios curriculares das licenciaturas, por meio de implementação de projetos de ensino, pesquisa e extensão e ações interdisciplinares; l) Democratizar 0 ingresso nas Escolas de Aplicação; m) Fortalecer os vínculos entre família-escola-comunidade; $n$ ) Divulgar a Política de Apoio às Escolas de Aplicação, enquanto campo de práxis pedagógica, por meio de: publicações, grupos de estudos e trabalho referente aos Colégios de Aplicação; o) Definir o sistema de acompanhamento e avaliação de desempenho das Escolas de Aplicação; $p$ ) Construir a identidade do colégio de Aplicação e clareza no que se refere a sua função social, política e cultural; q) Estabelecer uma política de interação entre as Escolas de Aplicação para: repensar práticas pedagógicas e/ ou administrativas; o intercâmbio entre professores o congraçamento de alunos; a divulgação de experiências einovações pedagógicas; r) Criação do Fórum Nacional de Escolas de Aplicação. (MANIFESTO, 2012).

Sem a pretensão de encerrar, mas com o intuito de nos provocar para novas leituras e novos encaminhamentos em relação à Instituição de Ensino, faz-se necessário repensar a identidade e a função social do Colégio de Aplicação e sua implicação no contexto das Licenciaturas e principalmente no Curso de Pedagogia da Universidade Estadual de Londrina.

Esse repensar possibilitará a articulação entre Ensino Superior e Educação Básica. Nesse sentido, inferimos que a escola não é o único local de aquisição do saber elaborado e não é o único modelo capaz de tornar exitosa a ação educativa da escola. Entretanto a escola é fruto de suas próprias contradições e, embora existam muitas alternativas, inclusive para a aquisição do saber elaborado, a escola é o caminho que pode ser válido enquanto uma das funções sociais e de educação.
Isto posto, o trabalho realizado no Colégio de Aplicação possibilitou pensar que é possível a concretização de uma articulação maior entre Ensino Superior e Educação Básica. Esta interação permitiu compreender a necessidade da valorização da ação docente, fazendo-nos constatar que o tripé: ensino pesquisa e extensão não devem restringir-se apenas ao espaço da Universidade, mas ser vivenciado em todos os níveis e modalidade de ensino, entendendo o professor como intelectual transformador, como já assinalou Gramsci (1982).

Dito isto, este ensaio teórico pretende contribuir para o fomento das reflexões e pesquisas sobre a possibilidade do Colégio de Aplicação se tornar de fato um laboratório de ensino para os cursos de graduação e stricto sensu da Universidade, contribuindo desta maneira com o contexto da formação inicial e continuada dos professores e demais profissionais da educação.

\section{REFERÊNCIAS}

BRASIL. Decreto $\mathbf{n}^{0}$ 19.851, de 11 de Abril de 1931. Disponivel em: <http://www2.camara.gov.br/legin/fed/ decret/1930-1939/decreto-19851-11-abril-1931-505837publicacao-1-pe.html>. Acesso em: 16 de set. de 2014.

\section{BRASIL. Repensando as escolas de aplicação.} Brasília: MEC, 1993.

BRASIL. Plano Decenal de Educação Para Todos: 1993 A 2003. Cadernos Educação Básica. SERIE Institucional. Volume V. Repensando as Escolas de Aplicação. MEC, 2003.

FRANGELLA, Rita de Cássia Prazeres. Colégio de Aplicação e a instituição de uma nova lógica de formação de professores: um estudo histórico no Colégio de Aplicação da Universidade do Brasil. In: Anais do I Congresso Brasileiro de História da Educação, 6 a 9 de nov. de 2009. Disponível em: <http://www.sbhe.org.br/ novo/congressos/cbhe1/anais/134_rita_de_cassia_p. pdf $>$. Acesso em: 16 de set. de 2014. 
KINPARA, Minoru Martins. Colégio de aplicação e a prática de ensino. 1997. $187 f$. Dissertação (Mestrado em Educação) Faculdade de Educação, Universidade Estadual de Campinas, Campinas, 1997. Disponível em: <http://www.bibliotecadigital.unicamp.br/ document/?code=vtls000115856>. Acesso em: 18 de set. de 2014 .

LEMME, Paschoal. O Manifesto dos Pioneiros da Educação Nova e suas repercussões na realidade educacional brasileira. In: Revista Brasileira Estudos Pedagógicos, Brasília, v.86, n.212, jan./ abr. 2005. p.163-178. Disponível em: <http:// www.inep.gov.br/pesquisa/bbe-online/det. asp?cod=64806\&type=P>. 16 de set. de 2014 .

MANIFESTO. 06/02/2012. I Congresso Nacional dos Colégios de Aplicação e I Mostra de Práticas de Ensino de Estágios, do PRODOCENCIA e do PIBID no Estado do Paraná. 06, 07 e 08 de fevereiro de 2012. Universidade Estadual de Londrina, Londrina/PR.
1. Doutora em Educação, Docente do Departamento de Educação e Diretora
Acadêmica da Pro Reitoria de Graduação da Universidade Estadual de Lon-
drina. E-mail: adrianatecnologia@yahoo.com.br
2. Doutora em Educação, Docente do Departamento de Educação da Univer-
sidade Estadual de Londrina. E-mail: marta.furlan@yahoo.com.br
3. Doutor em História, Docente da Universidade Norte do Paraná e do
Colégio de Aplicação da Universidade Estadual de Londrina. E-mail:
fls.londrina@yahoo.com.br 